\title{
Vitamin D intake, serum 25-hydroxy vitamin D and pulmonary function in paediatric patients with cystic fibrosis: a longitudinal approach
}

\author{
Nyanza K. L. M. Timmers ${ }^{1,2}$, Rebecca K. Stellato ${ }^{3}$, Cornelis K. van der Ent ${ }^{2,4}$, Roderick H. J. Houwen ${ }^{1,2}$ \\ and Janna W. Woestenenk ${ }^{1,2} *$ \\ ${ }^{1}$ Department of Paediatric Gastroenterology, University Medical Centre Utrecht, KE.04.133.1, P.O. Box 85500, 3508 GA \\ Utrecht, The Netherlands \\ ${ }^{2}$ Cystic Fibrosis Centre, University Medical Centre Utrecht, KH.01.419.0, P.O. Box 85500, 3508 GA Utrecht, The Netherlands \\ ${ }^{3}$ Department of Biostatistics, Julius Centre, University Medical Centre Utrecht, STR.6.131, P.O. Box 85500, 3508 GA Utrecht, \\ The Netherlands \\ ${ }^{4}$ Department of Paediatric Pulmonology, University Medical Centre Utrecht, KH.01.419.0, P.O. Box 85500, 3508 GA Utrecht, \\ The Netherlands
}

(Submitted 30 March 2018 - Final revision received 22 August 2018 - Accepted 24 September 2018 - First published online 16 November 2018)

\begin{abstract}
Pancreatic-insufficient children with cystic fibrosis (CF) receive age-group-specific vitamin D supplementation according to international CF nutritional guidelines. The potential advantageous immunomodulatory effect of serum 25-hydroxy vitamin D (25(OH)D) on pulmonary function (PF) is yet to be established and is complicated by CF-related vitamin D malabsorption. We aimed to assess whether current recommendations are optimal for preventing deficiencies and whether higher serum 25(OH)D levels have long-term beneficial effects on PF. We examined the longitudinal relationship between vitamin D intake, serum 25(OH)D and PF in 190 CF children during a 4-year follow-up period. We found a significant relationship between total vitamin $\mathrm{D}$ intake and serum $25(\mathrm{OH}) \mathrm{D}(\beta=0 \cdot 02 ; 95 \% \mathrm{CI} 0 \cdot 01,0 \cdot 03 ; P=0 \cdot 000)$. However, serum 25(OH)D decreased with increasing body weight $(\beta=-0 \cdot 79 ; 95 \% \mathrm{CI}-1 \cdot 28,-0 \cdot 29 ; P=0 \cdot 002)$. Furthermore, we observed a significant relationship between serum $25(\mathrm{OH}) \mathrm{D}$ and forced expiratory volume in $1 \mathrm{~s}(\beta=0 \cdot 056 ; 95 \% \mathrm{CI} 0 \cdot 01,0 \cdot 102 ; P=0 \cdot 018)$ and forced vital capacity $(\beta=0.045 ; 95 \% \mathrm{CI} 0 \cdot 008,0 \cdot 082 ; P=0.017)$. In the present large study sample, vitamin $\mathrm{D}$ intake is associated with serum $25(\mathrm{OH}) \mathrm{D}$ levels, and adequate serum 25(OH)D levels may contribute to the preservation of PF in children with CF. Furthermore, to maintain adequate levels of serum $25(\mathrm{OH}) \mathrm{D}$, vitamin D supplementation should increase with increasing body weight. Adjustments of the international CF nutritional guidelines, in which vitamin D supplementation increases with increasing weight, should be considered.
\end{abstract}

Key words: Cystic fibrosis: Serum 25-hydroxy vitamin D: Pulmonary function: Paediatric patients: Vitamin D

Cystic fibrosis (CF) is the most common life-threatening autosomal recessive disorder in the Caucasian population, with an incidence of one in 3600 births in the Netherlands ${ }^{(1)}$. CF is characterised by progressive pulmonary dysfunction. In addition, most patients have pancreatic insufficiency, which can lead to fat malabsorption and deficiencies of fat-soluble vitamins such as vitamin $\mathrm{D}^{(2,3)}$. International CF nutritional guidelines therefore recommend agegroup-specific vitamin D supplementation to maintain optimal serum 25-hydroxy vitamin D (25(OH)D) levels ${ }^{(2,4)}$.

An association between serum $25(\mathrm{OH}) \mathrm{D}$ and pulmonary function (PF) was observed in the general population ${ }^{(4)}$, in paediatric patients with asthma ${ }^{(5)}$ and in adults with chronic obstructive pulmonary disease ${ }^{(6,7)}$. However, whether this beneficial effect also applies to paediatric patients with $\mathrm{CF}$ is unknown, as the study results were inconclusive ${ }^{(8)}$ or limited to a cross-sectional design ${ }^{(9,10)}$.

Furthermore, little is known about the daily practice of vitamin D intake, vitamin D supplementation and its association with serum $25(\mathrm{OH}) \mathrm{D}$ in paediatric $\mathrm{CF}$ patients, as previous studies lacked data on dietary vitamin $\mathrm{D}$ intake ${ }^{(11-14)}$, were limited by a cross-sectional design ${ }^{(12,15)}$ or were conducted in the context of a trail in which the study sample was prescribed very high dosages of vitamin $\mathrm{D}$, far above those used in current clinical practice ${ }^{(14,16-19)}$. We therefore set out to record the dietary vitamin D intake, vitamin D supplementation and the long-term relationship with serum $25(\mathrm{OH}) \mathrm{D}$. In addition, we describe the

Abbreviations: \% pred., percentage of the predicted value for a given height, age and sex; 25(OH)D, 25-hydroxy vitamin D; CF, cystic fibrosis; CFRD, cystic fibrosis-related diabetes; FEV1, forced expiratory volume in $1 \mathrm{~s}$; FVC, forced vital capacity; PF, pulmonary function.

* Corresponding author: J. W. Woestenenk, email j.w.woestenenk@gmail.com

$\dagger$ Present address: Nutricia Research, Utrecht, The Netherlands. 
association between serum 25(OH)D and $\mathrm{PF}$ in a large study sample of paediatric patients with CF during a 4-year follow-up.

\section{Methods \\ Study sample}

This retrospective study included Dutch children and adolescents with proven $\mathrm{CF}$ and proven pancreatic insufficiency who received medical care at the $\mathrm{CF}$ centre of the University Medical Centre Utrecht between January 2012 and March 2016. The diagnosis CF was confirmed by a positive sweat test and/or the presence of a known CF gene mutation on each cystic fibrosis transmembrane conductance regulator gene. Pancreatic insufficiency was defined by a documented history of fat malabsorption with a coefficient of fat absorption of $<85 \%$ and/or a faecal elastase of $<15 \mu \mathrm{g} / \mathrm{g}$ stool or chymotrypsin activity $<3 \mathrm{U} / \mathrm{g}$ per stool. Included patients had at least one serum 25(OH)D measurement obtained between January 2012 and March 2016 during the annual CF check-up. Excluded were one transplanted patient and two patients with serum $25(\mathrm{OH}) \mathrm{D}$ values above $200 \mathrm{nmol} / \mathrm{l}$, as we suspected that these values were the result of measurement errors. Written informed consent was given by all patients or by parents or guardians of young patients. The study was performed according to the guidelines of the Medical Ethics Committee of the University Medical Centre Utrecht.

\section{Dietary intake assessment}

Yearly, patients were asked to complete a 3-d record of their food and beverage intake, consisting of two consecutive weekdays and one weekend day whenever possible. The dietary vitamin D intake was calculated for each assessment according to a standardised approach using the Dutch food composition table (2010) established by the Dutch Nutrition Centre.

The prescribed vitamin D supplements as documented in medical records were considered as supplementary vitamin D intake. The prescribed dosages were based upon the European Union guideline of 2002, which advices a daily supplementary vitamin D intake of $10-50 \mu \mathrm{g}(400-2000 \mathrm{IU})$ for all ages ${ }^{(20)}$. In patients with an insufficient serum $25(\mathrm{OH}) \mathrm{D}$ level, the supplement dosage was adjusted, the increase being subject to the opinion of the physician in charge. Total vitamin D intake was calculated by adding dietary and supplementary intake.

The vitamin D intake (dietary intake, prescribed supplementation and total intake) was expressed as $\mu \mathrm{g} / \mathrm{d}$. Owing to the wide body weight range of the study sample $(5 \cdot 0-84.5 \mathrm{~kg})$, we subsequently expressed the dietary, supplementary and total intake as $\mu \mathrm{g} / \mathrm{kg}$ body weight per $\mathrm{d}$.

\section{Clinical measurements}

Serum 25(OH)D levels in blood were routinely measured as part of the annual check-up and analysed by electrochemiluminescence sandwich immunoassay (Cabas E411; Roche) which was calibrated against National Institute of Standards and Technology standard material; performance was monitored daily using Lyphochek control material (Bio-Rad Laboratories). Mean CV\% was within $8.7 \%$. Measurements were classified according to months with high (June-October) and low (November-May) UVB exposure ${ }^{(15)}$.

Height and weight were measured to the nearest $0.1 \mathrm{~cm}$ and $0 \cdot 1 \mathrm{~kg}$, respectively, during annual check-ups. Weight, height and BMI were compared with reference values using $z$-scores as calculated by specialised software of the Dutch Growth Foundation (Growth Analyser 4 RCT, 2010, Dutch Growth Foundation). Yearly, patients from 10 years of age onwards were screened for glucose tolerance by the modified oral glucose tolerance test $(1.75 \mathrm{~g} / \mathrm{kg}$ glucose, maximum dosage $75 \mathrm{~g})$. An overnight fasting plasma glucose level and a 2-h postprandial glucose level were measured. Those having glucose levels $>11.1 \mathrm{mmol} / 1$ after oral glucose tolerance test, or fasting glucose $>7.0 \mathrm{mmol} / \mathrm{l}$ were categorised as CF-related diabetes $(\mathrm{CFRD})^{(21)}$. CF-related liver disease (CFLD) was diagnosed according to the Colombo criteria ${ }^{(22)}$. Serum IgG, as a marker of chronic inflammation, was measured concurrently with serum $25(\mathrm{OH}) \mathrm{D}$ and expressed as $\mathrm{g} / \mathrm{l}$. The use of systemic corticosteroids in each year was recorded.

$\mathrm{PF}$ was assessed as forced expiratory volume in $1 \mathrm{~s}\left(\mathrm{FEV}_{1}\right)$ and forced vital capacity (FVC) and expressed as a percentage of the predicted value for a given height, age and sex (\% pred.) using the Global Lung Function Initiative reference values ${ }^{(23)}$. For each child, the highest PF measured in the preceding calendar year was used, beginning at the age of 6 years. PF tests up to 2016 were included.

\section{Statistical analysis}

Categorical variables were examined using descriptive statistics. Continuous variables were assessed on normality and skewness. Due to repeated measures on individual patients in different years of age, children were stratified according to age year (year $0=$ birth to $<1$ year, year $1=1$ to $<2$ years, etc.) and measurements of dietary, supplemental and total vitamin D intake, intake per kg body weight and serum 25(OH)D were described accordingly.

To assess whether the initial measurements of total vitamin D intake and PF were related to serum 25(OH)D levels, children were categorised based on their serum $25(\mathrm{OH}) \mathrm{D}$ as having levels $<50 \mathrm{nmol} / 1$ (deficient), levels between 50 and $75 \mathrm{nmol} / 1$ (sufficient) or $>75 \mathrm{nmol} / \mathrm{l}$ (high sufficient), based upon current European Union guidelines in which serum 25(OH)D levels $\geq 50 \mathrm{nmol} / 1$ are considered sufficient ${ }^{(3)}$. Age, vitamin D intake (dietary, prescribed supplementation and total) and PF were compared cross-sectionally amongst the categorised serum 25(OH)D levels using one-way ANOVA or the Kruskal-Wallis test. To evaluate the effect of total vitamin $\mathrm{D}$ intake on serum $25(\mathrm{OH}) \mathrm{D}$ over time, linear mixed-effect regression models were used. These models allow inclusion of varying numbers of measurements per child, irregular observation times and missed observations. Age, sex, body weight and season were included as fixed effects. A random intercept and a random slope for age 
per child accounted for associations between measurements within children.

We also examined the longitudinal effect of serum $25(\mathrm{OH}) \mathrm{D}$ on $\mathrm{PF}\left(\mathrm{FEV}_{1} \%\right.$ pred. and $\mathrm{FVC} \%$ pred.), using linear mixed-effect regression. Included were age, sex, $z$-score BMI, IgG, CFLD, CFRD, corticosteroid use and season as fixed effects and a random intercept and slope for age. Sample size was determined by the availability of data from the medical records. Exact effect sizes for longitudinal data are difficult to estimate and require many assumptions, so the current study presents a conservative estimate here. A sample size of 190 would provide $80 \%$ power to detect a correlation of at least 0.20 between serum $25(\mathrm{OH}) \mathrm{D}$ and $\mathrm{PF}$ using a two-sided hypothesis test with a significance level of $0 \cdot 05$. Statistical analysis was performed using the Statistical Package for the Social Sciences Computer Software version 21 (IBM).

\section{Results}

\section{Patient characteristics}

Data of 190 paediatric patients (95\% Caucasian) were eligible for inclusion. In these patients, we obtained 545 measurements of serum 25(OH)D and 353, 532 and 346 measurements of dietary, supplementary and total vitamin D intake, respectively. A total of 408 measurements of PF were obtained in 157 children aged 6 years and older. Demographic and clinical characteristics of patients at the time of inclusion are described in Table 1.

\section{Descriptive baseline results}

Median dietary intake at time of inclusion was $4 \cdot 1$ (interquartile range (IQR) $2 \cdot 3-8 \cdot 0) \mu \mathrm{g} / \mathrm{d}$, supplementary intake was 10 (IQR 10-11.3) $\mu \mathrm{g} / \mathrm{d}$ and total intake was 14.7 (IQR 12-21) $\mu \mathrm{g} / \mathrm{d}$. All remained relatively constant over the subsequent age-years (online Supplementary Table S1). Dietary, supplementary and total vitamin D intake are expressed as $\mu \mathrm{g} / \mathrm{kg}$ per $\mathrm{d}$, and serum $25(\mathrm{OH}) \mathrm{D}$ decreased with increasing age (Fig. 1).

A total of $76 / 190$ ( $40 \%$ ) patients had deficient, $73 / 190$ (38.4\%) patients had sufficient and 41/190 (21.6\%) had high-sufficient serum $25(\mathrm{OH}) \mathrm{D}$ levels at time of inclusion. The distribution of dietary vitamin $\mathrm{D}$ intake was comparable among the serum $25(\mathrm{OH}) \mathrm{D}$ classes $(P=0 \cdot 170)$, while the distribution of supplementary and total vitamin $\mathrm{D}$ intake was significantly higher in classes with higher serum 25(OH)D levels $(P=0.010$ and $P=0 \cdot 018$, respectively). Children in the lower serum $25(\mathrm{OH}) \mathrm{D}$ classes were significantly older $(P=0 \cdot 000)$. Further, the distribution of $\mathrm{FEV}_{1} \%$ pred. and $\mathrm{FVC} \%$ pred. did not differ among the serum 25(OH)D classes $(P=0.075$ and $P=0.149$, respectively).

\section{Longitudinal analysis of vitamin D intake and serum 25-hydroxy vitamin D}

Longitudinally, there was a significant relationship between total vitamin D intake and serum 25(OH)D $(\beta=0.02 ; 95 \%$ CI 0.01 , $0 \cdot 03$ ), which remained significant after correction for potential confounders (Table 2 ). In our study sample, on average, each $100 \mathrm{IU}(2.5 \mu \mathrm{g})$ increase in vitamin $\mathrm{D}$ resulted in a $2 \mathrm{nmol} / \mathrm{l}$

Table 1. Demographical and clinical characteristics of 190 children and adolescents with cystic fibrosis at the time of inclusion (Medians and interquartile ranges (IQR); numbers of subjects and percentages)

\begin{tabular}{|c|c|c|c|}
\hline Continuous variables & Median & IQR & Total number of patients \\
\hline Serum 25(OH)D (nmol/l) & 55 & $34-70$ & 190 \\
\hline Dietary vitamin $D$ intake $(\mu \mathrm{g} / \mathrm{d})$ & $4 \cdot 1$ & $2 \cdot 3-8$ & 126 \\
\hline Supplementary vitamin D intake $(\mu \mathrm{g} / \mathrm{d})$ & 10 & $10-11 \cdot 3$ & 186 \\
\hline Total vitamin D intake $(\mu \mathrm{g} / \mathrm{d})$ & 14.7 & $12-21$ & 125 \\
\hline \multicolumn{4}{|l|}{ Pulmonary function } \\
\hline $\mathrm{FEV}_{1} \%$ of predicted ${ }^{*}$ & 89 & $78-100$ & 157 \\
\hline FVC $\%$ of predicted ${ }^{*}$ & 94 & $86-103$ & 157 \\
\hline Age (years) & 11.14 & $6 \cdot 01-14.47$ & 190 \\
\hline Age at diagnosis (years) & 0.30 & $0.02-0.80$ & 188 \\
\hline BMI (z-score) & -0.34 & $-0.85-0.21$ & 190 \\
\hline $\lg G(g / l)$ & 9.96 & $7 \cdot 53-12 \cdot 70$ & 168 \\
\hline Categorical variables & Number of subjects & Percentage of total (\%) & Total number of patients \\
\hline Sex (male) & 91 & 47.9 & 190 \\
\hline Genotype & & & 188 \\
\hline Df508del homozygote & 120 & 63.8 & \\
\hline Df508del heterozygote & 57 & $30 \cdot 3$ & \\
\hline Other & 11 & 5.9 & \\
\hline Season of $25(\mathrm{OH}) \mathrm{D}$ measurement & & & 190 \\
\hline Low UVB month† & 101 & $53 \cdot 2$ & \\
\hline High UVB month† & 89 & $46 \cdot 8$ & \\
\hline CFRD & 10 & $5 \cdot 3$ & 190 \\
\hline CFLD & 46 & $24 \cdot 2$ & 190 \\
\hline Systemic corticosteroid use & 55 & 34.8 & 158 \\
\hline
\end{tabular}

25(OH)D, 25-hydroxy vitamin D; FEV , forced expiratory volume in $1 \mathrm{~s}$; FVC, forced vital capacity; CFRD, cystic fibrosis-related diabetes mellitus; CFLD, cystic fibrosis-related liver disease.

* Percentage of predicted as calculated according to the Global Lung Function Initiative reference values ${ }^{(23)}$

† Low UVB months, November-May; high UVB months, June-October. 


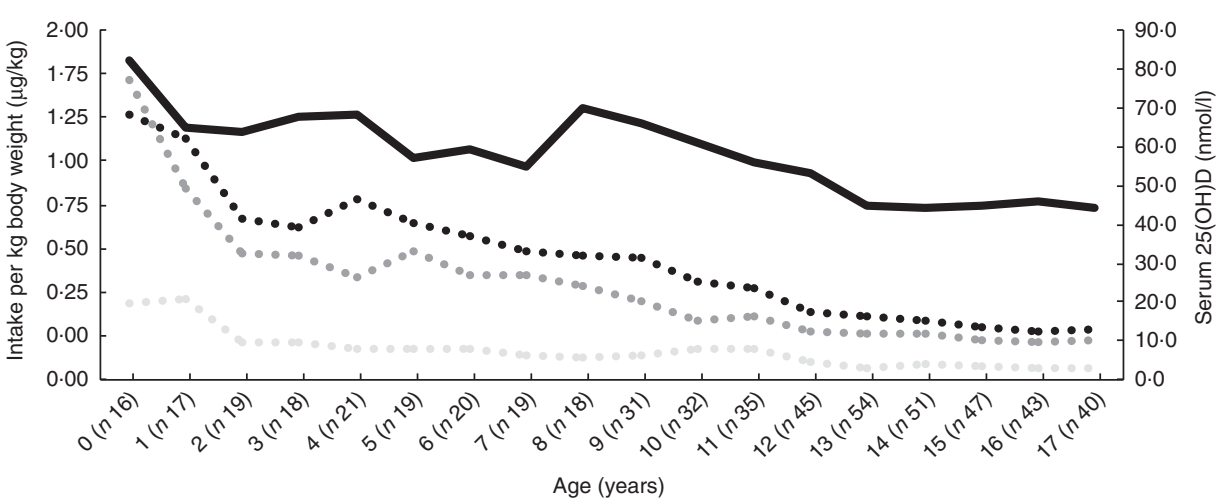

Fig. 1. Median serum 25 -hydroxy vitamin $D(25(\mathrm{OH}) \mathrm{D})$ and dietary, supplementary and total vitamin $\mathrm{D}$ intake at the time of inclusion, expressed as $\mu \mathrm{g} / \mathrm{kg}$ body weight per d in 190 patients with cystic fibrosis, stratified according to year of age. . . . , Total vitamin D $(\mu \mathrm{g} / \mathrm{kg}$ per d); . . , supplementary vitamin D $(\mu \mathrm{g} / \mathrm{kg}$ per d); . . . , dietary vitamin $\mathrm{D}(\mu \mathrm{g} / \mathrm{kg}$ per $\mathrm{d})$; $\longrightarrow$, serum $25(\mathrm{OH}) \mathrm{D}$.

Table 2. Predictive factors of change in serum 25-hydroxy vitamin D expressed as $\mathrm{nmol} / \mathrm{l}$ in 190 children and adolescents with cystic fibrosis, using a mixed effect regression model (Regression coefficients and $95 \%$ confidence intervals)

\begin{tabular}{lcrr}
\hline Variables & Regression coefficient & $95 \% \mathrm{Cl}$ & $P$ \\
\hline Total vitamin D intake $(\mu \mathrm{g} / \mathrm{d})$ & 0.82 & $0.54,1.10$ & $<0.001$ \\
Age (years) & 0.87 & $-0.84,2.58$ & 0.317 \\
Sex (male) & -3.47 & $-9.47,2.81$ & 0.277 \\
Weight (kg) & -0.79 & $-1.20,-0.29$ & 0.002 \\
Season (high UVB months) & 9.01 & $4.84,13.18$ & $<0.001$ \\
\hline
\end{tabular}

(95\% CI 1.0, 3.0) increase in serum 25(OH)D. Further, each $\mathrm{kg}$ increase in body weight resulted in a $0 \cdot 79-\mathrm{nmol} / \mathrm{l}$ decline $(95 \% \mathrm{CI}$ $-1 \cdot 28,-0 \cdot 29)$ in serum $25(\mathrm{OH}) \mathrm{D}$. Serum $25(\mathrm{OH}) \mathrm{D}$ was significantly higher in months with high UVB (June-October) $(\beta=9.01 \mathrm{nmol} / 1 ; 95 \% \mathrm{CI} 4.84,13 \cdot 18)$. Age and sex were not significantly associated with serum $25(\mathrm{OH}) \mathrm{D}$.

\section{Longitudinal analysis of serum 25-hydroxy vitamin D and pulmonary function}

We observed a significant relationship between serum 25(OH)D and $\mathrm{PF}$, expressed as $\mathrm{FEV}_{1} \%$ pred. and $\mathrm{FVC} \%$ pred. after adjustment for age, sex, $z$-score BMI, IgG, CFLD, CFRD and corticosteroid usage. In our study sample, each 20-nmol/1 increase in serum 25(OH)D resulted in an increase of $1.12 \%$ (95\% CI 0.2, 2.04) of $\mathrm{FEV}_{1} \%$ pred. and $0.9 \%$ (95\% CI 0.16, 1.64) FVC\% pred. (Table 3). Furthermore, we found a negative association between PF and age and CFRD, while PF and BMI had a positive association.

\section{Discussion}

This longitudinal study in a large cohort of children and adolescents with CF, with a 4-year follow-up, showed a significant relationship between total vitamin D intake (dietary and supplemental intake) and serum 25(OH)D and between serum 25(OH)D and PF.

To the best of our knowledge, this is the first longitudinal study on serum $25(\mathrm{OH}) \mathrm{D}$ in paediatric patients with $\mathrm{CF}$, including both dietary vitamin $\mathrm{D}$ intake and vitamin D supplementation dosages as prescribed in daily clinical CF care. In our study sample, and in accordance with other North-European CF populations ${ }^{(10)}$, the dietary vitamin $\mathrm{D}$ intake attributed one-third of the total vitamin $\mathrm{D}$ intake. In our study, the median dietary vitamin $\mathrm{D}$ intake remained fairly constant throughout the age-years, while serum $25(\mathrm{OH}) \mathrm{D}$ significantly decreased with age. We found no relationship between dietary vitamin D intake and serum 25(OH)D as reported previously ${ }^{(15)}$. However, total vitamin $\mathrm{D}$ intake was clearly related to serum $25(\mathrm{OH}) \mathrm{D}$, indicating the importance of vitamin $\mathrm{D}$ supplementation to obtain and maintain adequate serum $25(\mathrm{OH}) \mathrm{D}$.

Longitudinally, we found a relationship between total vitamin D intake and serum 25(OH)D. This is in line with a previous study in 360 adults with CF with a mean initial serum 25(OH)D of $47 \mathrm{nmol} / 1$ and a mean initial supplemental vitamin D intake of $16 \cdot 2 \mu \mathrm{g} / \mathrm{d}(646 \mathrm{IU} / \mathrm{d})$ in which an increase of $10-25 \mu \mathrm{g} / \mathrm{d}$ (400-1000 IU/d) or counselling led to high sufficient serum $25(\mathrm{OH}) \mathrm{D}$ values in $82 \%$ of the subjects ${ }^{(13)}$. Several intervention studies in paediatric CF patients, with serum 25(OH)D levels $<75 \mathrm{nmol} / \mathrm{l}$, found an increase in serum 25(OH)D to $>75 \mathrm{nmol} / 1$ in $54-94 \%$ of the study sample when prescribed extreme amounts of vitamin D supplements (1250 $\mu \mathrm{g} /$ week (50 000 IU/ week) up to $15000 \mu \mathrm{g}$ (600000 IU) stoss therapy) ${ }^{(16-19)}$. In contrast to these findings, Hillman et al. ${ }^{(24)}$ found no extra effect of $50 \mu \mathrm{g}$ (2000 IU) vitamin $\mathrm{D} / \mathrm{d}$ supplementation in a small crossover trial in 15 paediatric CF patients. However, these patients had significantly higher serum 25(OH)D levels at baseline (median $83 \mathrm{nmol} / \mathrm{l}$ ) than our study sample. It is questionable whether an increase in the already high serum levels can be expected, as previous studies have indicated that vitamin $\mathrm{D}$ intake has to increase exponentially, as higher serum $25(\mathrm{OH}) \mathrm{D}$ levels are to be reached ${ }^{(13,25)}$. 
Table 3. Predictive factors of respectively forced expiratory volume in $1 \mathrm{~s}\left(\mathrm{FEV}_{1}\right) \%$ of predicted and forced vital capacity (FVC)\% of predicted in 158 children and adolescents with cystic fibrosis, using a mixed effect regression model (Regression coefficients and $95 \%$ confidence intervals)

\begin{tabular}{|c|c|c|c|c|c|c|}
\hline & \multicolumn{3}{|c|}{$\mathrm{FEV}_{1} \%$ of predicted } & \multicolumn{3}{|c|}{ FVC\% of predicted } \\
\hline & Regression coefficient & $95 \% \mathrm{Cl}$ & $P$ & Regression coefficient & $95 \% \mathrm{Cl}$ & $P$ \\
\hline Serum 25(OH)D (nmol/l) & 0.06 & $0.01,0.10$ & 0.018 & 0.05 & $0.01,0.80$ & 0.017 \\
\hline Age (years) & -1.58 & $-2.11,-1.05$ & $<0.001$ & -0.53 & $-0.99,-0.08$ & 0.022 \\
\hline Sex (male) & $-2 \cdot 18$ & $-6 \cdot 57,2 \cdot 21$ & 0.328 & 0.31 & $-3.43,4.05$ & 0.870 \\
\hline BMI (z-score) & 1.87 & $0.36,3.38$ & 0.002 & 1.67 & $0.44,2.90$ & 0.008 \\
\hline $\lg G(g / l)$ & -0.42 & $-0.85,0.02$ & 0.060 & -0.30 & $-0.66,0.05$ & 0.096 \\
\hline CFRD & $-7 \cdot 75$ & $-12 \cdot 55,-2 \cdot 95$ & 0.002 & $-6 \cdot 26$ & $-10 \cdot 19,-2 \cdot 34$ & 0.002 \\
\hline CFLD & $-2 \cdot 36$ & $-6 \cdot 14,1.41$ & 0.219 & -1.90 & $-5.05,1.25$ & 0.236 \\
\hline Systemic corticosteroid use & $-1 \cdot 23$ & $-3.03,0.58$ & 0.182 & 0.19 & $-1 \cdot 26,1.64$ & 0.801 \\
\hline
\end{tabular}

25(OH)D, 25-hydroxy vitamin D; CFRD, cystic fibrosis-related diabetes mellitus; CFLD, cystic fibrosis-related liver disease.

Previous studies also reported an inverse association between age and serum $25(\mathrm{OH}) \mathrm{D}^{(8,11,26-28)}$ in paediatric patients with $\mathrm{CF}$, although no conclusive explanation was given. We found that children with higher levels of serum $25(\mathrm{OH}) \mathrm{D}$ were significantly younger, with the highest serum $25(\mathrm{OH}) \mathrm{D}$ levels in patients below the age of 4 years old. While having a fairly constant absolute vitamin $\mathrm{D}$ intake, the intake per kg body weight of patients below the age of 4 years was more than double compared with adolescents, leading to the assumption that body weight might influence serum $25(\mathrm{OH}) \mathrm{D}$ levels. Our longitudinal model indeed indicated that an increasing body weight is related to a decreasing serum $25(\mathrm{OH}) \mathrm{D}$. This might be due to the dilution of vitamin $\mathrm{D}$ in larger body volumes ${ }^{(29,30)}$ which occurs as children grow and weight increases ${ }^{(25,31)}$. As increasing age was not sufficiently matched by a concurrent increase in (supplementary) vitamin D intake, a downward trend of serum 25(OH)D with age was observed.

To note, current $\mathrm{CF}$ guidelines provide recommendations for large age-groups (age $\leq 1$ year, $>1-10$ years, 10 years onwards); although direct extrapolation of our results, which were based upon the 2002 guidelines, should be done with caution, children of different ages, and with large differences in body weight, still share the same recommendation. It might be more appropriate to use smaller age intervals or body weight, with yearly evaluation as described in the CF-specific guidelines $^{(3)}$.

We and others found a significant relationship between serum 25(OH)D and PF in children and adolescents with $\mathrm{CF}$, which remained after correcting for multiple confounders known to affect $\mathrm{PF}^{(9)}$. Several studies have addressed the relationship between vitamin D intake and PF although with conflicting results ${ }^{(9-12,32)}$. Cross-sectional studies in both paediatric and in mixed paediatric and adult populations found a relationship between $\mathrm{FEV}_{1} \%$ pred. and serum $25(\mathrm{OH}) \mathrm{D}^{(9-11)}$. The only previous longitudinal study in 130 paediatric patients with CF with a median follow-up of 4 years did not find a longitudinal relationship with $\mathrm{PF}^{(8)}$. However, this study did not account for confounders that significantly affect the PF such as age, $z$-score BMI and CFRD, as we and others found these variables are indeed correlated with $\mathrm{PF}$. Therefore, a positive effect of serum 25(OH)D on PF in the study by McCauley et $a l .{ }^{(8)}$ may have been blurred.
A recent pilot study by Pincikova et $a l .{ }^{(14)}$ in sixteen patients (10 adults) did find a positive relationship between change in serum 25(OH)D and PF ( $\mathrm{FEV}_{1}$ and FVC). Our study seems to indicate that this relationship is also present in paediatrics with $\mathrm{CF}$.

Any beneficial effect of serum $25(\mathrm{OH}) \mathrm{D}$ on $\mathrm{PF}$ has been attributed to the immunomodulatory potentials of vitamin $\mathrm{D}^{(33)}$. Metabolised serum 25(OH)D in airway epithelia exhibits antimicrobial effects by regulation of anti-microbial peptides ${ }^{(34)}$ and anti-inflammatory effects by pro-inflammatory cytokines ${ }^{(35)}$. This could reduce chronic pulmonary colonisation and thereby aid in the long-term preservation of $\mathrm{PF}^{(12)}$.

Several limitations of this study can be mentioned. First, keeping food records might lead to alterations of the diet and to over- and/or under-reporting. Second, differences in seasonal variation in individuals might not be detected as the time of year in which the dietary intake recorded remained fairly constant over the study years. In addition, we followed the clinical practice and thereby did not measure adherence to vitamin D supplementation or accounted for missed dosages. Finally, as this study was retrospective in design, the causal effect of serum $25(\mathrm{OH}) \mathrm{D}$ on $\mathrm{PF}$ we found should ideally be reproduced in a prospective randomised trial.

\section{Conclusion}

In conclusion, in this large study sample, a significant relationship between total vitamin D intake (dietary and supplemental) and serum 25(OH)D and an inverse relationship between body weight and serum $25(\mathrm{OH}) \mathrm{D}$ were described in paediatric CF patients. In addition, higher serum $25(\mathrm{OH}) \mathrm{D}$ levels were associated with higher $\mathrm{FEV}_{1} \%$ pred. and $\mathrm{FVC} \%$ pred. These findings suggest that vitamin D supplementation should increase with increasing body weight, as adequate serum 25(OH)D levels may contribute to the preservation of PF. Adjustments of the recommendations in which vitamin D supplementation increases with increasing weight, to maintain adequate serum $25(\mathrm{OH}) \mathrm{D}$ levels in children with $\mathrm{CF}$, should be considered.

\section{Acknowledgements}

This research received no specific grant for any funding agency, commercial or not-for-profit sectors. 
N. K. L. M. T. and J. W. W. contributed to the conception and design and coordination of the research, carried it out, analysed the data and drafted the manuscript; R. K. S. participated in the statistical analysis and critically revised the manuscript. R. H. J. H. participated in the design of the study and drafted the manuscript. C. K. v. d. E. critically revised the manuscript; all authors agree to be fully accountable for ensuring the integrity and accuracy of the work. All authors have read and approved the final manuscript.

The authors declare that there are no conflicts of interest.

\section{Supplementary material}

For supplementary material/s referred to in this article, please visit https://doi.org/10.1017/S0007114518003021

\section{References}

1. Slieker MG, Uiterwaal CSPM, Sinaasappel M, et al. (2005) Birth prevalence and survival in cystic fibrosis: a national cohort study in the Netherlands. Chest 128, 2309-2315.

2. O'Sullivan BP \& Freedman SD (2009) Cystic fibrosis. Lancet 373, 1891-1904.

3. Turck D, Braegger CP, Colombo C, et al. (2016) ESPENESPGHAN-ECFS guidelines on nutrition care for infants, children, and adults with cystic fibrosis. Clin Nutr 35, 557-577.

4. Black PN \& Scragg R (2005) Relationship between serum 25-hydroxyvitamin $\mathrm{D}$ and pulmonary function in the Third National Health and Nutrition Examination Survey. Chest 128, 3792-3798.

5. Pojsupap S, Iliriani K, Sampaio TZAL, et al. (2015) Efficacy of high-dose vitamin $\mathrm{D}$ in pediatric asthma: a systematic review and meta-analysis. J Asthma 52, 382-390.

6. Janssens W, Bouillon R, Claes B, et al. (2010) Vitamin D deficiency is highly prevalent in COPD and correlates with variants in the vitamin D-binding gene. Thorax 65, 215-220.

7. Ferrari M, Schenk K, Papadopoulou C, et al. (2011) Serum 25 -hydroxy vitamin D and exercise capacity in COPD. Thorax 66, 544-545.

8. McCauley LA, Thomas W, Laguna TA, et al. (2014) Vitamin D deficiency is associated with pulmonary exacerbations in children with cystic fibrosis. Ann Am Thorac Soc 11, 198-204.

9. Sexauer WP, Hadeh A, Ohman-Strickland PA, et al. (2015) Vitamin D deficiency is associated with pulmonary dysfunction in cystic fibrosis. J Cyst Fibros 14, 497-506.

10. Pincikova T, Nilsson K, Moen IE, et al. (2011) Inverse relation between vitamin $D$ and serum total immunoglobulin $G$ in the Scandinavian Cystic Fibrosis Nutritional Study. Eur J Clin Nutr 65, 102-109.

11. Green D, Carson K, Leonard A, et al. (2008) Current treatment recommendations for correcting vitamin D deficiency in pediatric patients with cystic fibrosis are inadequate. J Pediatr 153, 554-559.

12. Simoneau T, Bazzaz O, Sawicki GS, et al. (2014) Vitamin D status in children with cystic fibrosis: associations with inflammation and bacterial colonization. Ann Am Thorac Soc 11, 205-210.

13. Stephenson A, Brotherwood M, Robert R, et al. (2007) Cholecalciferol significantly increases 25-hydroxyvitamin D concentrations in adults with cystic fibrosis. Am J Clin Nutr 85 , $1307-1311$.
14. Pincikova T, Sandberg JK \& Hjelte L (2017) Clinical impact of vitamin $\mathrm{D}$ treatment in cystic fibrosis: a pilot randomized, controlled trial. Eur J Clin Nutr 71, 203-205.

15. Rovner AJ, Stallings VA, Schall JI, et al. (2007) Vitamin D insufficiency in children, adolescents, and young adults with cystic fibrosis despite routine oral supplementation. Am J Clin Nutr 86, 1694-1699.

16. Simoneau T, Sawicki GS, Milliren CE, et al. (2015) A randomized controlled trial of vitamin $\mathrm{D}$ replacement strategies in pediatric CF patients. J Cyst Fibros 15, 234-241.

17. Green DM, Leonard AR, Paranjape SM, et al. (2010) Transient effectiveness of vitamin $\mathrm{D}_{2}$ therapy in pediatric cystic fibrosis patients. J Cyst Fibros 9, 143-149.

18. Boas SR, Hageman JR, Ho LT, et al. (2009) Very high-dose ergocalciferol is effective for correcting vitamin D deficiency in children and young adults with cystic fibrosis. J Cyst Fibros 8, 270-272.

19. Shepherd D, Belessis Y, Katz T, et al. (2013) Single high-dose oral vitamin $\mathrm{D}_{3}$ (stoss) therapy - a solution to vitamin $\mathrm{D}$ deficiency in children with cystic fibrosis? J Cyst Fibros 12, 177-182.

20. Sinaasappel M, Stern M, Littlewood J, et al. (2002) Nutrition in patients with cystic fibrosis: a European Consensus. J Cyst Fibros 1, 51-75.

21. Moran A, Pillay K, Becker DJ, et al. (2014) Management of cystic fibrosis-related diabetes in children and adolescents. Pediatr Diabetes 15, 65-76.

22. Colombo C, Russo MC, Zazzeron L, et al. (2006) Liver disease in cystic fibrosis. J Pediatr Gastroenterol Nutr 43, Suppl. 1, S49-S55.

23. Quanjer PH, Stanojevic S, Cole TJ, et al. (2012) Multi-ethnic reference values for spirometry for the 3-95-yr age range: the global lung function 2012 equations. Eur Respir J 40, 1324-1343.

24. Hillman LS, Cassidy JT, Popescu MF, et al. (2008) Percent true calcium absorption, mineral metabolism, and bone mineralization in children with cystic fibrosis: effect of supplementation with vitamin D and calcium. Pediatr Pulmonol 43, $772-780$.

25. Zittermann A, Ernst JB, Gummert JF, et al. (2014) Vitamin D supplementation, body weight and human serum 25hydroxyvitamin D response: a systematic review. Eur J Nutr 53, 367-374.

26. Lansing AH, McDonald C, Patel RA, et al. (2015) Vitamin D deficiency in pediatric patients with cystic fibrosis: associated risk factors in the northern United States. South Med J 108, 164-169.

27. Norton L, Page S, Sheehan M, et al. (2015) Prevalence of inadequate vitamin D status and associated factors in children with cystic fibrosis. Nutr Clin Pract 30, 111-116.

28. Chavasse RJ, Francis J, Balfour-Lynn I, et al. (2004) Serum vitamin D levels in children with cystic fibrosis. Pediatr Pulmonol 38, 119-122.

29. Drincic AT, Armas LAG, Van Diest EE, et al. (2012) Volumetric dilution, rather than sequestration best explains the low vitamin D status of obesity. Obesity 20, 1444-1448.

30. Pannu PK, Zhao Y \& Soares MJ (2016) Reductions in body weight and percent fat mass increase the vitamin $D$ status of obese subjects: a systematic review and metaregression analysis. Nutr Res 36, 201-213.

31. Weishaar $\mathrm{T} \&$ \& Rajan S (2015) Importance of body weight and skin color in determining appropriate vitamin $\mathrm{D}_{3}$ supplement doses for children and adolescents. Pediatr Res 77, 370-375. 
32. Vanstone MB, Egan ME, Zhang JH, et al. (2015) Association between serum 25-hydroxyvitamin D level and pulmonary exacerbations in cystic fibrosis. Pediatr Pulmonol 50 441-446.

33. Herscovitch K, Dauletbaev N \& Lands LC (2014) Vitamin D as an anti-microbial and anti-inflammatory therapy for cystic fibrosis. Paediatr Respir Rev 15, 154-162.
34. Yim S, Dhawan P, Ragunath C, et al. (2007) Induction of cathelicidin in normal and CF bronchial epithelial cells by 1,25-dihydroxyvitamin D(3). J Cyst Fibros 6, 403-410.

35. McNally P, Coughlan C, Bergsson G, et al. (2011) Vitamin D receptor agonists inhibit pro-inflammatory cytokine production from the respiratory epithelium in cystic fibrosis. $J$ Cyst Fibros 10, 428-434. 